\section{Effects of interpolated escape training on discriminated leverpress avoidance}

\author{
SANDRA L. MANKJNS and DONALD M. RAGUSA \\ Bowling Green State University, Bowling Green, Ohio 43402
}

Using a discriminated leverpress avoidance procedure, it was shown that interpolated escape training (i.e., CS-omission training) causes a decrement in subsequent avoidance performance. After initially receiving 150 avoidance trials, the experimental groups received 10,30 , or 90 escape trials, followed immediately by an additional 75 avoidance trials (test trials). The experimental groups all differed significantly on the first 25 test trials from the control, which received 225 uninterrupted avoidance trials. The obtained decrement was discussed in terms of its relevance to a related study by Bloom and Campbell and the "learned-helplessness" literature.

In a study on discriminated-avoidance behavior by Bloom \& Campbell (1966), it was reported that either prior or interpolated CS-omission trials (interpolated unsignaled escape training) led to a marked decrement in avoidance performance when the CS was reinstated. Furthermore, this decrement tended to increase as the number of interpolated escape trials increased. However, there may be reason to doubt the generality of the CS-omission effect. The basic concern involves the use of the shuttlebox procedure. Theios, Lynch, \& Lowe (1966) contend that in the shuttlebox there is a high-strength competing response to the CS that is incompatible with the avoidance response. That is, there is a tendency for the animal not to reenter a compartment in which he was just shocked. Since the interpolated escape training necessarily involves the exposure to shock on every CS-omission trial, it is reasonable to assume that this procedure would augment this high-strength competing response to the CS.

In oxder to test the generality of the Bloom and Campbell study, an experiment was carried out in which the effect of interpolated escape training on discriminated leverpress avoidance performance was investigated. It was predicted that a decrement in performance should be obtained after reinstatement of the $C S$, if the Bloom and Campbell experiment had any applicability beyond the shuttlebox situation.

\section{SUBJECTS}

The Ss were 39 male albino rats from the Sprague-Dawley strain ranging from 94 to 144 days of age. The Ss were individually housed and maintained on ad lib food and water.

\section{APPARATUS}

The apparatus consisted of a chamber made of 1 -in. transparent Plexiglas, with metal plates attached to both end walls. The internal dimensions were $12 \times 6 \times 8$ in.
A removable inner ceiling was inserted in the box $4 \frac{1}{2}$ in. above the grid floor. The floor consisted of $1 / 4-$ in. stainless steel rods placed $3 / 4$ in. apart. Shock was applied to the grid and end plates via a Lehigh Valley Electronics (LVE) 1671 constant-current shock scrambler. A lever, 2 in. wide, protruded $1 / 2$ in. through one of the metal walls 2 in. above the floor. A downward force of $20 \mathrm{~g}$ was required to operate the lever. Two 6-W lamps were located on the wall opposite the manipulandum, 5 in. above the grid and $1 \frac{1}{2}$ in. apart. The box was held in place in a Scientific Prototype, SPC-300, soundproof chamber. A $455 \mathrm{C}$ Grason-Stadler noise generator, the indigenous speaker, and associated amplification equipment provided all auditory stimulation. Background illumination was provided by a 6-W lamp. All events were tape programmed using LVE solid-state modules. All response events, as well as all shocks received, were recorded on an LVE 13214 multipen event recorder.

\section{PROCEDURE}

There were three experimental groups and one control group, with eight Ss randomly assigned to each group. On the day prior to the beginning of the experiment, all Ss received 40 avoidance shaping trials using either a barpress or a bar-release response. The response topography was the same throughout all experimental phases. Discontinuous shock consisting of .1 sec on and $1 \mathrm{sec}$ off, with an intensity of $.25 \mathrm{~mA}$, was used during shaping. The ITI used during the entire experiment was a variable interval averaging $35 \mathrm{sec}(20-50 \mathrm{sec})$ and the CS-UCS interval was $5 \mathrm{sec}$.

On Day 2 all Ss initially received 150 discriminated-avoidance trials. During discriminated avoidance, the compound CS consisted of the onset of two 6-W lamps and a change in white-noise level from 70 to $80 \mathrm{~dB} 5 \mathrm{sec}$ prior to the onset of the UCS. The UCS consisted of a .25-mA discontinuous pulse of shock with a .1 -sec on period and a 2 -sec off period. If a response was not made during this $5-\mathrm{sec}$ period, a response during the 2 -sec off period only was then required to terminate both CS and UCS. An S was disqualified if he failed to meet the criterion of $32 \%$ avoidance by the end of the last block of 25 trials during initial acquisition. Six Ss were lost due to failure to meet criterion. One S was lost due to equipment failure.

Immediately following the initial 150 avoidance trials, the $\mathrm{CS}$ was omitted for 10,30 , or 90 trials for Experimental Groups G-10, G-30, and G-90, respectively. During this period $S$ could escape only during the off part of the shock cycle and could do nothing to prevent the onset of shock. Immediately following the interpolated escape, the experimental groups received an additional 75 avoidance trials.

The control group (G-0) received avoidance training uninterrupted for a total of 225 trials.

\section{RESULTS}

For all data, analyses trials were grouped into blocks of 25 trials per block. A 4 by 6 repeated-measures analysis of variance was performed on the acquisition data, using the number of avoidance responses. The only effect found to be significant was that due to trials $(F=62.6, \mathrm{df}=5 / 40, \mathrm{p}<.01)$. Figure 1 presents the mean number of avoidance responses for the last block of trials prior to interpolated escape (Block 6) and the three blocks of test trials following interpolated escape (Blocks 7, 8, and 9) for all groups. The performance of the experimental groups decreased after interpolated escape during the first 25 trials, while the performance of the control group was at a somewhat higher level. Given that the decrement was apparent only on the first block of test trials, the main data analysis discussed here focuses only on these 25 trials. A one-way analysis of variance was performed on the scores obtained by subtracting the number of avoidances of Block 6 from that obtained on Block 7. This yiclded a significant effect due to treatment $(\mathrm{F}=4.78, \mathrm{df}=3 / 28$, $\mathrm{p}<.01$ ). Individual comparisons using a Newman-Keuls analysis indicated that the difference scores for all groups were significantly different from the control (G-10, $p<.05 ; \quad G-30, \quad p<.05 ;$ G-90, $\mathrm{p}<.01)$. All other possible comparisons were not significant.

Rank-order coefficients of correlation were calculated between number of avoidances on Block 6 and Block 7 for each experimental group. The correlations were positive and significant (G-10, $r=.786, p<.05 ; G-30, I=.786 . p<.05 ;$ G-90, $r=.792, p<.05$ ), suggesting that 


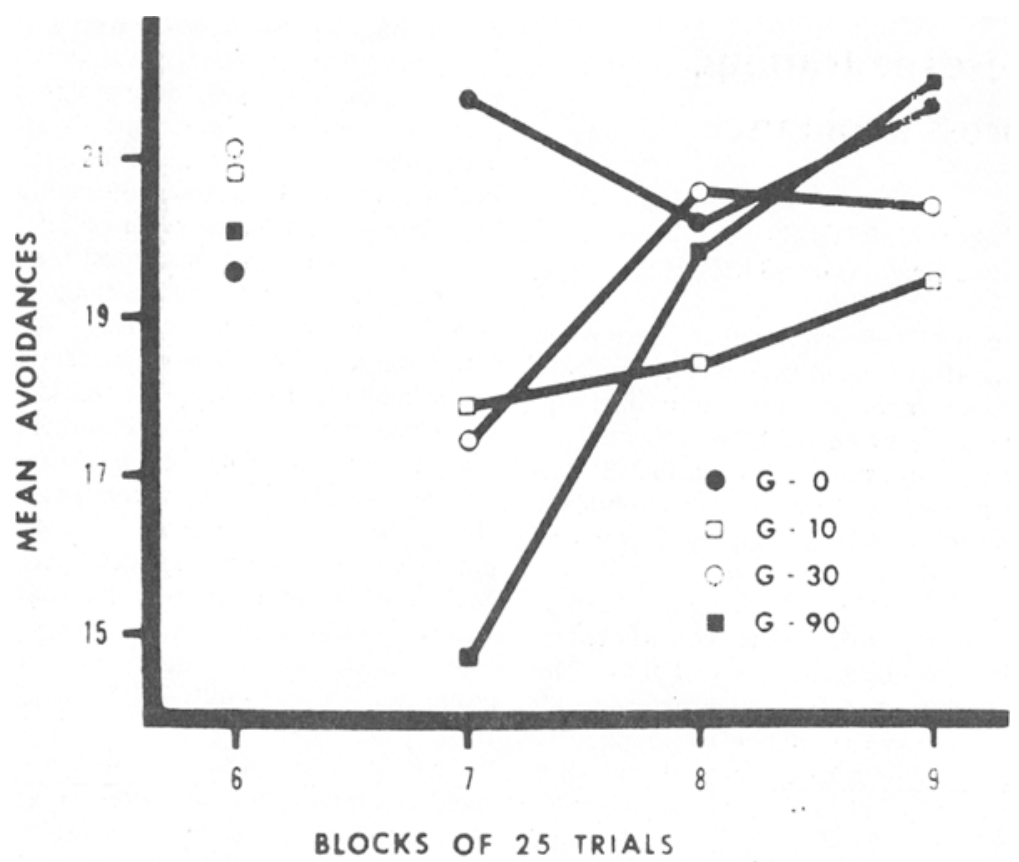

Fig. 1. Mean number of avoidance responses for the last 25 preinterpolated escape trials (Block 6) and all 75 test trials, 25 trials per block.

the higher the level of avoidance prior to interpolated escape. the better the performance after interpolated escape. DISCUSSION

The results of this study, in agreement with Bloom and Campbell. show that interpolated escape training causes a decrement in subsequent avoidance performance. However, the present study does not agree with the previous study on three points. First, the obtained decrement in the present study did not increase systematically as the number of interpolated escape trials increased, as was the case in the Bloom and Campbell study, although G-90 did have the greater decrement. Second, Bloom and Campbell reported that the magnitude of the drop in subsequent performance was approximately the same regardless of the initial level of performance. The data of this study indicate that interference tended to be greatest for those animals that had performed most poorly on the initial avoidance acquisition. The third point of disagreement with the Bloom and Campbell study is that their data indicate that this decrement does not disappear by the end of testing. Superficially, this may suggest a permanent impairment in performance. In the present study the decrement was most clearly observable immediately after reinstatement of the CS and virtually disappeared after the first block of test trials. This discrepancy may be due to the limited number of test trials (15 trials) employed by Bloom and Campbell. The present study offered a substantially greater opportunity for recovery ( 75 trials).

The obtained decrement could possibly be related to the "learned-helplessness phenomenon." The studies in this area indicate that exposure to inescapable and unavoidable preshock in a Pavlovian harness subsequently interferes with the emergence of escape/avoidance responding in the shuttlebox (Maier, Seligman, \& Solomon, 1968; Overmier \& Seligman. 1967). When, however, the preshock experience is controllable (i.e., escapable), subsequent escape/avoidance responding is not impaired (Seligman \& Maier, 1967). These investigators contend that a loss of control over shock termination presumably causes $S$ to become passive and reduces his incentive for making an active instrumental response, thus impairing subsequent performance. This concept of control over shock termination is not consistent with the results of either the Bloom and Campbell study or the present one. Implicit in the use of an interpolated escape procedure is that $S$ retains the ability to terminate the aversive events. Maier et al. in attempting to explain the results of the Bloom and Campbell study, maintained that the decrement caused by the interpolated escape was due to "removal of S's control over shock onset [p. 44]." However, they give no further evidence in support of this statement.

There are two procedural differences that may account for the discrepancies between the literature dealing with learned helplessness and that dealing with interpolated escape. First, the test phase for the learned-helplessness group is always run $24 \mathrm{~h}$ subsequent to the preshock condition; in the Bloom and Campbell study and in the present study, the test phase follows the interpolated escape immediately. The second difference is in the use of a warning signal. Rarely during the preshock session do Seligman and his colleagues use a signal. In the present study a signal is employed during both phases of discriminated avoidance. This might imply that it is the loss of the warning signal during interpolated escape rather than the escape contingency per se that is the important factor in the present investigation.

\section{REFERENCES}

BLOOM. J. U.. \& CAIIPBELL. B. A. Effects of CS omission following avoidance learning. Journal of Experimental Psychology, 1966. 72, 36-39.

MAIER. S. F., SEligMaN, M. E. P., \& SOLOMON, R. L. Pavlovian fear conditioning and learned helplessness: Effects of escape and avoidance behavior of a) CS-L'S contingency and $b)$ the independence of the L'S and voluntary responding. In B. A. Campbell and R. Church (Eds.). Punishment. New York: Appleton-Century-Crofts. 1969. Pp. 299-342.

OVERIIIER. J. B.. \& SELIGMAN, II. E. P. Effects of inescapable shock upon subsequent escape and avoidance responding. Joumal of Comparative \& Physiological Psychology. $1967.63 .28-33$

SELIGMAN, M. E. P.. \& MAIER, S. F. Failure to escape traumatic shock. Journal of Experimental Psychology. 1967. 74. 1-9.

THEIOS, J. A., LYNCH. D. A., \& LOWE. W. F., JR. Differential effects of shock intensity on one-way and shuttle avoidance conditioning. Journal of Experimental Psychology. 1966. 72, 294-299. 